Sādhanā, Vol. 18, Part 6, December 1993, pp. 927-941. (C) Printed in India.

\title{
Time-domain-finite-wave analysis of the engine exhaust system by means of the stationary-frame method of characteristics. Part II. Computed results and experimental corroboration thereof
}

\author{
V H GUPTA and M L MUNJAL*
}

Department of Mechanical Engineering, Indian Institute of Science, Bangalore 560012, India

MS received 19 August 1992; revised 19 January 1993

\begin{abstract}
Time-domain-finite-wave analysis of engine exhaust systems is usually carried out by means of the method of characteristics. The theory and the computational details of the stationary-frame method have been worked out in the accompanying paper (part I). In this paper (part II), typical computed results are given and discussed. A setup designed for experimental corroboration is described. The results obtained from the simulation are found to be in good agreement with experimental observations.
\end{abstract}

Key words. Noise control; engine simulation; method of characteristics.

\section{Introduction}

Using the computational procedure described in the accompanying paper (part I) (Gupta \& Munjal 1993), an exhaust system of a four-stroke, compression-ignition, single-cylinder engine was simulated (Gupta 1991). The particulars are described later in $\S 3$ where the simulation results are compared with the experimental observations. Before that, in the following section, typical computational results are presented. This brings out the basic qualities of the computational procedure and the program.

\section{Typical computational results}

The computations were performed using a blow-down pressure of $0.343 \mathrm{MPa}^{\dagger}$ and a blow-down temperature of $1300 \mathrm{~K}$. These values were obtained at full-load conditions for the engine. Typical results of such a simulation for an exhaust pipe of $1.0 \mathrm{~m}$ length

\footnotetext{
* For correspondence
}

${ }^{\dagger} 1 \mathrm{MPa}=10 \mathrm{bar}$ 


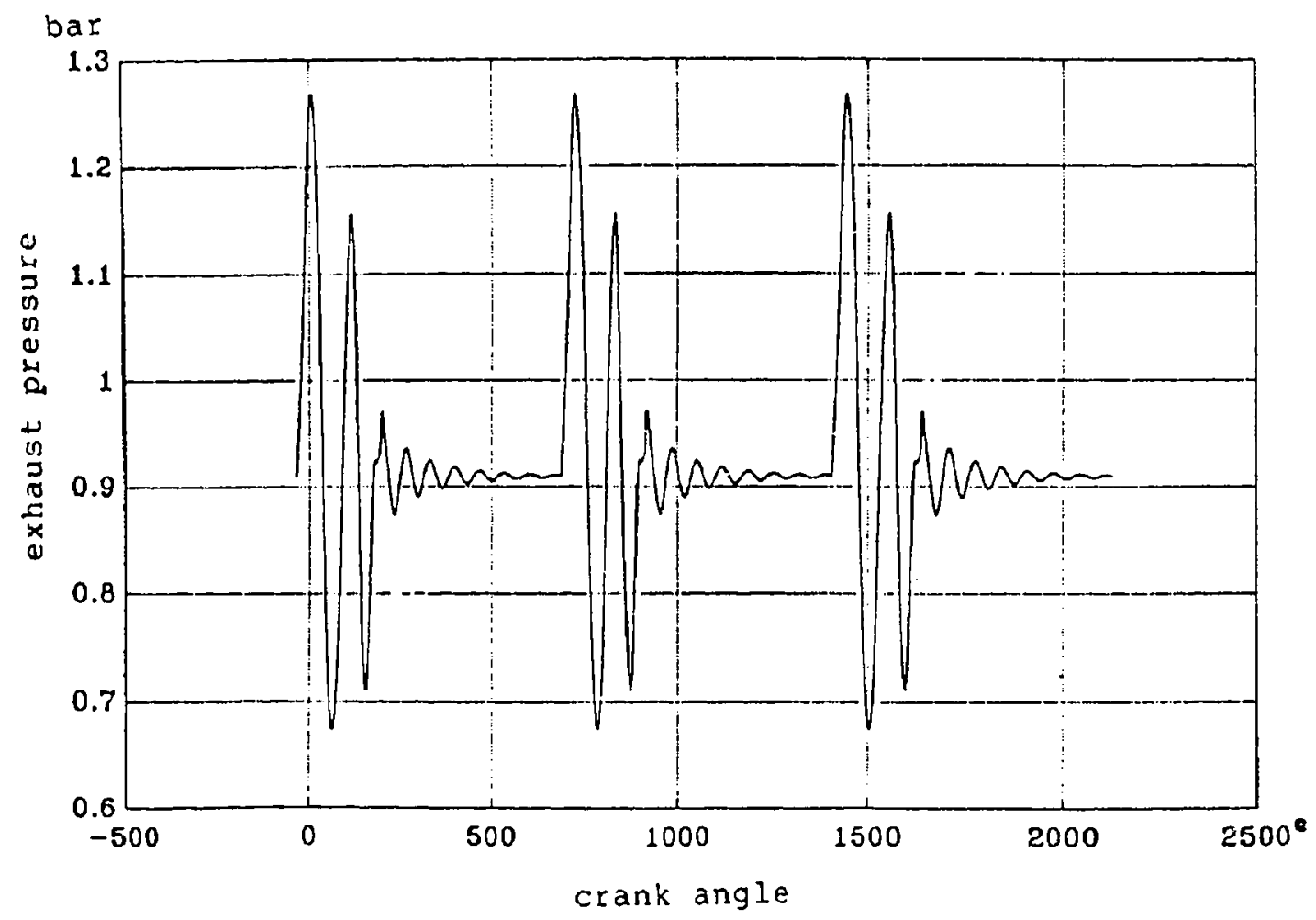

Figure 1. Exhaust pressure for a pipe of length $1 \mathrm{~m}$ for the last three cycles. (1 $\mathrm{Bar}=10^{5} \mathrm{~Pa}=0 \cdot 1 \mathrm{MPa}$.)

are shown in figure 1, where exhaust pressure (pressure at the point immediately after the valve, i.e. the first point in the pipe) is plotted against crank angle for three consecutive cycles after the steady state is attained. It is clear from the figure that the pressure-crank angle history repeats itself after the steady state is attained. However, observing the repetition in pressure history to check for the steady state will be too tedious and therefore one makes use of certain average parameters to do the same. For example, the total mass entering the exhaust pipe from the cylinder (MEX) and that leaving the tail pipe over the complete cycle (MTP) are computed. Also, the mean tail-pipe temperature (TTPM) and the mean tail pipe density (RHEM) are computed over a complete cycle. These values become steady or constant as the steady state is reached. The evolution of these values for a typical case is shown in table 1. It is evident from the table that, after a few cycles, the values repeat themselves exactly. Figure 1 represents the values of the last three cycles of this table. It can be easily seen that the overall average parameters tabulated verily indicate the approach of

Table 1. The evolution of mean values with computational cycles.

\begin{tabular}{lcccc}
\hline Cycle & MEX $(\mathrm{kg})\left(\times 10^{-3}\right)$ & MTP $(\mathrm{kg})\left(\times 10^{-3}\right)$ & RHEM $\left(\mathrm{kg} / \mathrm{m}^{3}\right)$ & TTPM $(\mathrm{K})$ \\
\hline 1 & 0.4800 & 0.4135 & 0.4436 & 693.6 \\
2 & 0.4800 & 0.4600 & 0.4519 & 677.1 \\
3 & 0.4800 & 0.4599 & 0.4509 & 678.6 \\
4 & 0.4800 & 0.4596 & 0.4509 & 678.7 \\
5 & 0.4800 & 0.4596 & 0.4509 & 678.7 \\
6 & 0.4800 & 0.4596 & 0.4509 & 678.7 \\
\hline
\end{tabular}


Table 2. Computational requirements for exhaust pipe of different lengths.

\begin{tabular}{lccc}
\hline $\begin{array}{l}\text { Length of the } \\
\text { exhaust pipe } \\
\text { in } \mathrm{m}\end{array}$ & $\begin{array}{c}\text { Number of cycles } \\
\text { for steady state }\end{array}$ & $\begin{array}{c}\text { Computational time } \\
\text { per cycle (s) }\end{array}$ & $\begin{array}{c}\text { Total time } \\
\text { (s) }\end{array}$ \\
\hline 0.5 & 3 & 12.5 & 62.5 \\
1.0 & 5 & $23 \cdot 3$ & 116.5 \\
2.0 & 10 & $49 \cdot 5$ & 495 \\
3.0 & 15 & 73.2 & 1098 \\
5.0 & 22 & 125.0 & 2750 \\
\hline
\end{tabular}

steady state. The number of cycles required to reach the steady state is dependent on various parameters like the muffler geometry, the engine speed etc. The computational time (on an IBM PC with Intel 80486 processor) required for the attainment of the steady state cycle for exhaust pipes of different lengths is tabulated in table 2 . It is evident from the table that the computational time per cycle is almost a linear function of the pipe length. This is as anticipated because the more the complexity in terms of number of elements and various pipe lengths, the more the number of grid points and therefore larger the computer time. Moreover, it can be seen in the same table (table 2) that the number of cycles required to reach the steady state also increases almost linearly with the exhaust pipe length. This too is expected because the longer the pipe, the more the time taken for waves to travel along the length and therefore the more the number of cycles required. In fact this can be put in a quantitative fashion as explained in the next paragraph.

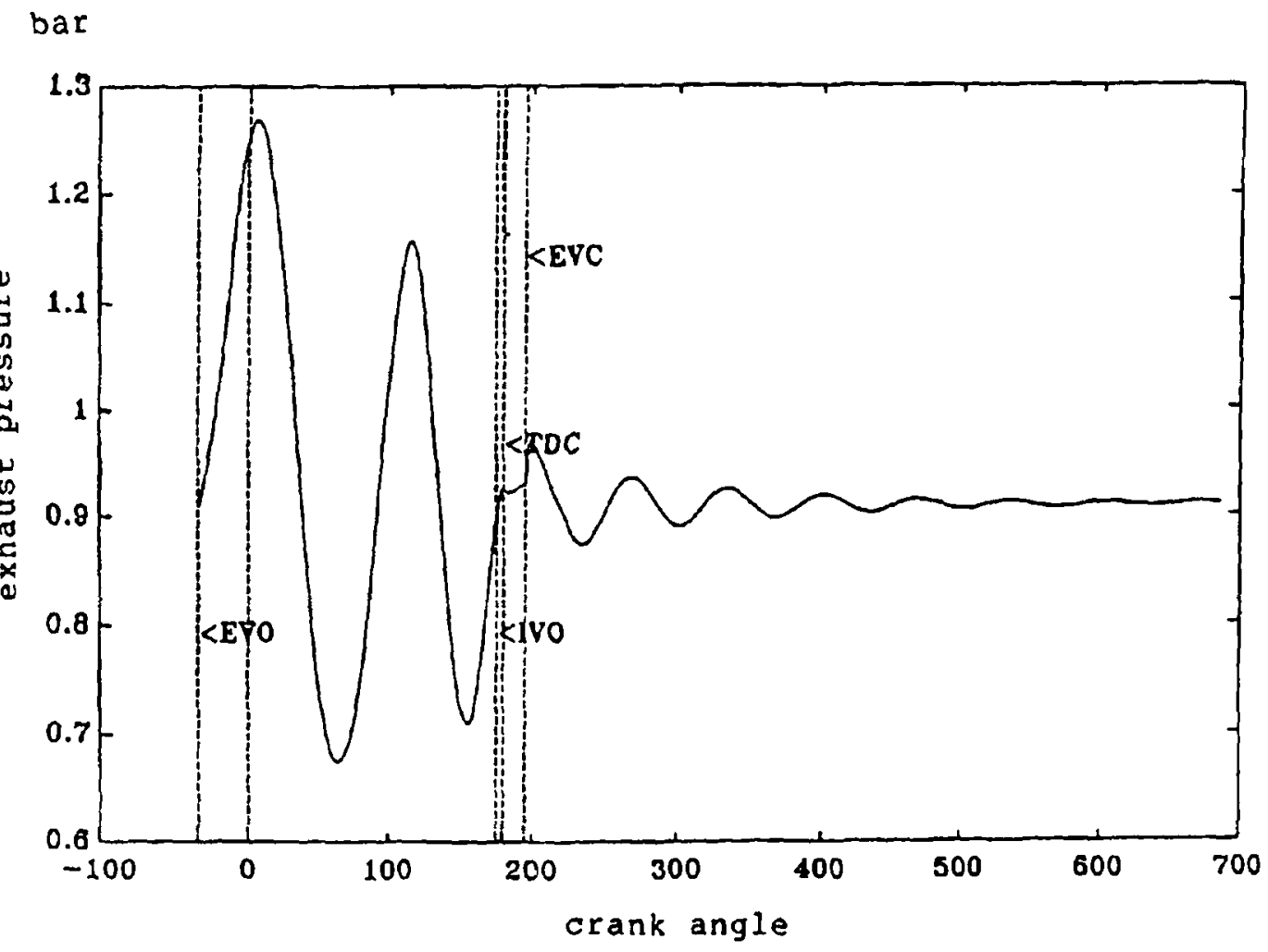

Figure 2. Variation of exhaust pressure for an exhaust pipe of $1 \mathrm{~m}$ length. 


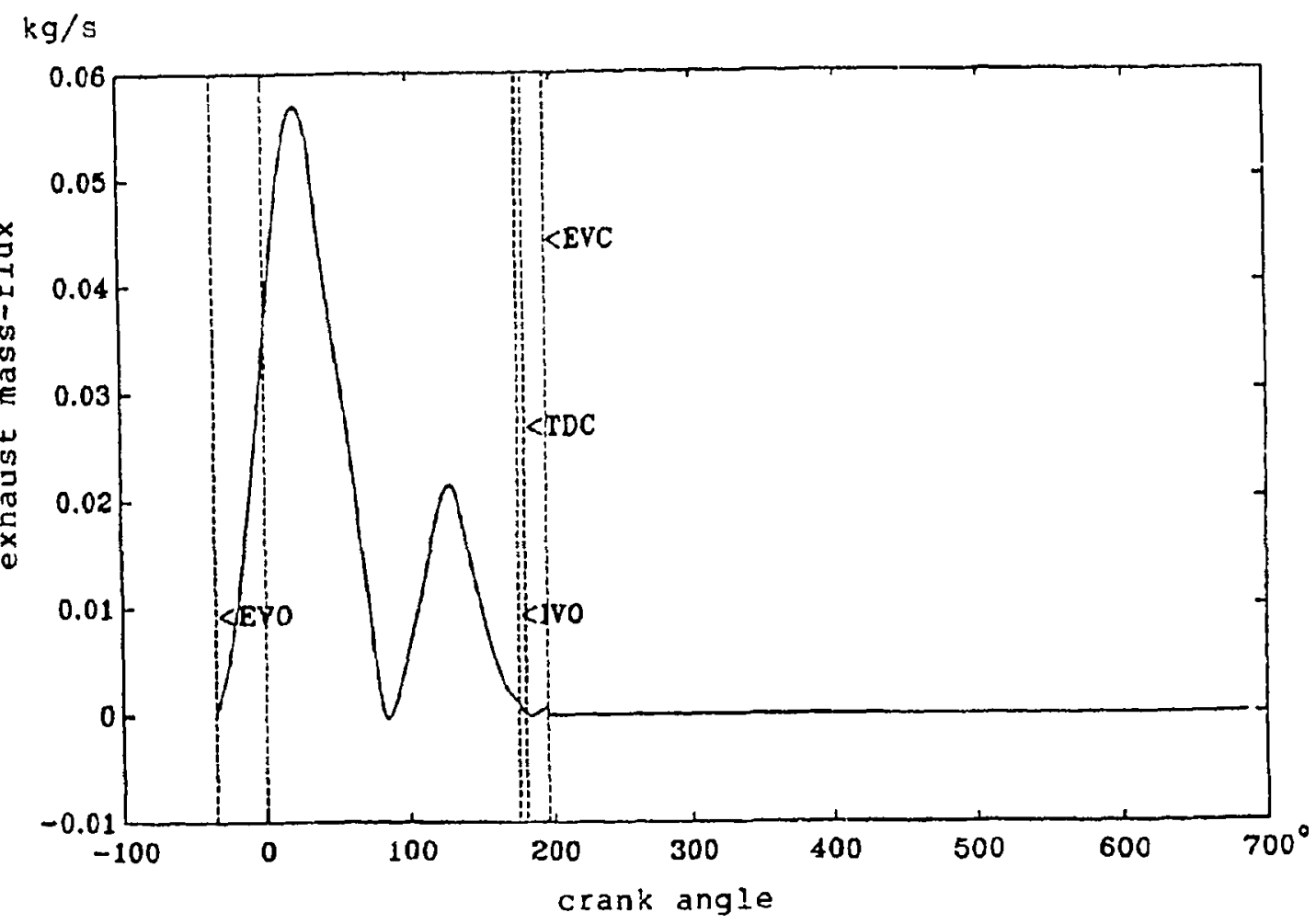

Figure 3. Variation of exhaust mass flux for an exhaust pipe of $1 \mathrm{~m}$ length.

The velocity of the gases in the pipe is not a very strong function of the pipe length. The mean flow velocity in the pipe for various pipe lengths remains constant. As an engineering approximation, this value (which is specific to the particular engine as such) is around $30 \mathrm{~m} / \mathrm{s}$. As is well known, the entropy wave travels with the particle and therefore the time taken for the entropy wave to traverse across the length a sufficient number of times (say about five times) linearly increases with pipe length. Engine RPM being constant, the number of revolutions and hence the number of cycles completed during the traverse also increase linearly with the pipe length. Hence, the number of cycles required for the attainment of the steady state also increases almost linearly with the exhaust pipe length. In the case of more complex mufflers, however, it is difficult to make any such prediction because, with the presence of area discontinuities and the like, the interactions required for the computations to reach the steady state cannot be put simplistically. Nevertheless, as an approximation one could consider the whole muffler volume as a single pipe of some equivalent length and so get a fair idea of the computational behaviour. This equivalent length can be obtained by dividing the total muffler volume by the exhaust pipe cross-sectional area.

The program was run for various values of $\Delta \theta$ to investigate its effect on the results of simulation. For exhaust systems consisting of simple pipes, values as high as $4^{\circ}$ gave pressure value predictions comparable to those computed with $2^{\circ}$ or $1^{\circ} \Delta \theta$. However, noise radiation predictions, being sensitive to pressure derivatives, were not as accurate as the others. The results with $2^{\circ}$ were better and those with $1^{\circ}$ showed further improvement. However, the improvements in the quality were not substantial. For mufflers with simple area discontinuities, $\Delta \theta$ values larger than $1^{\circ}$ gave rise to numerical instabilities at the area discontinuities while iterating with the NewtonRaphson method. This too is quite expected because the Newton-Raphson method 


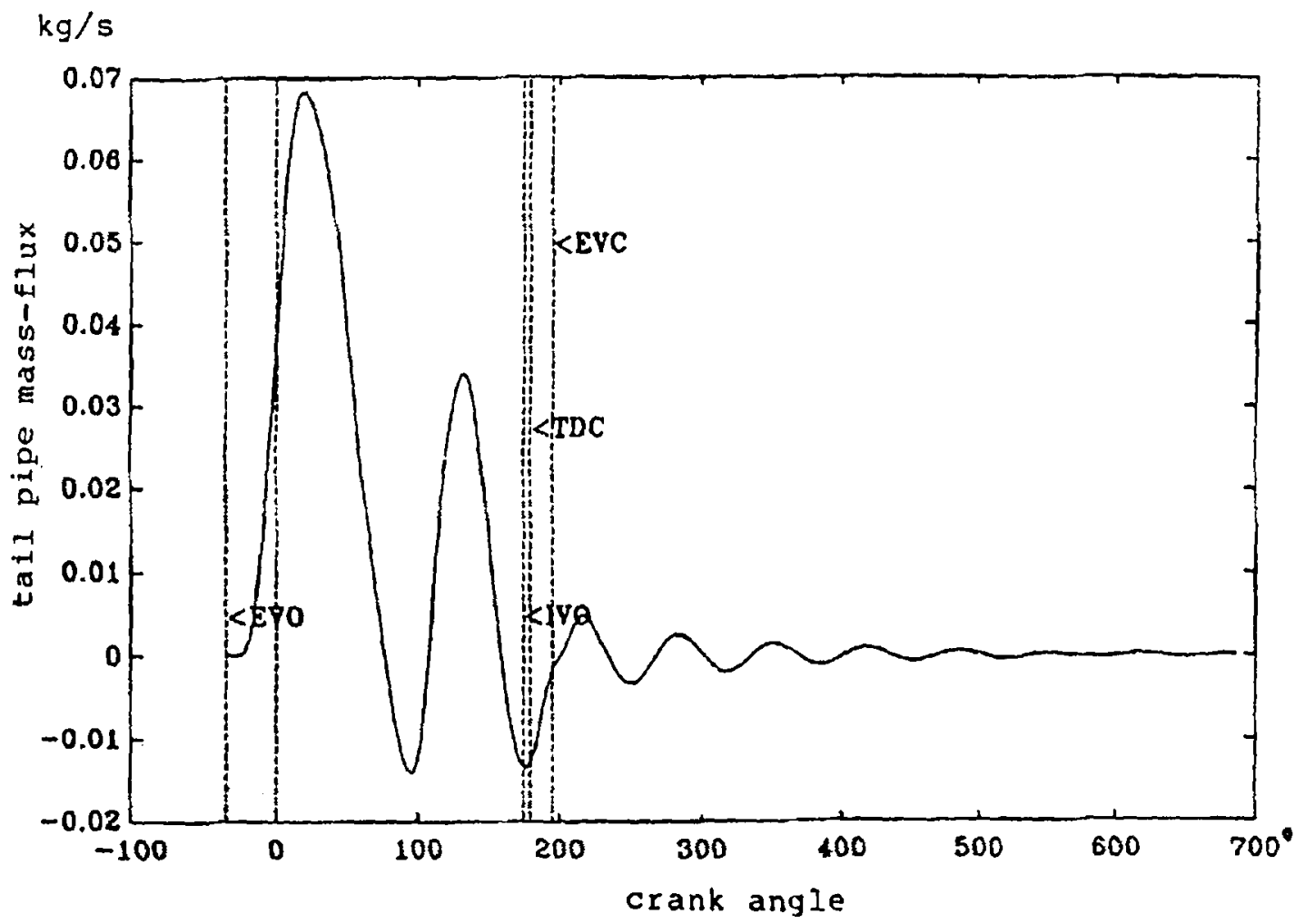

Figure 4. Variation of the tail-pipe mass flux for an exhaust pipe of $1 \mathrm{~m}$ length.

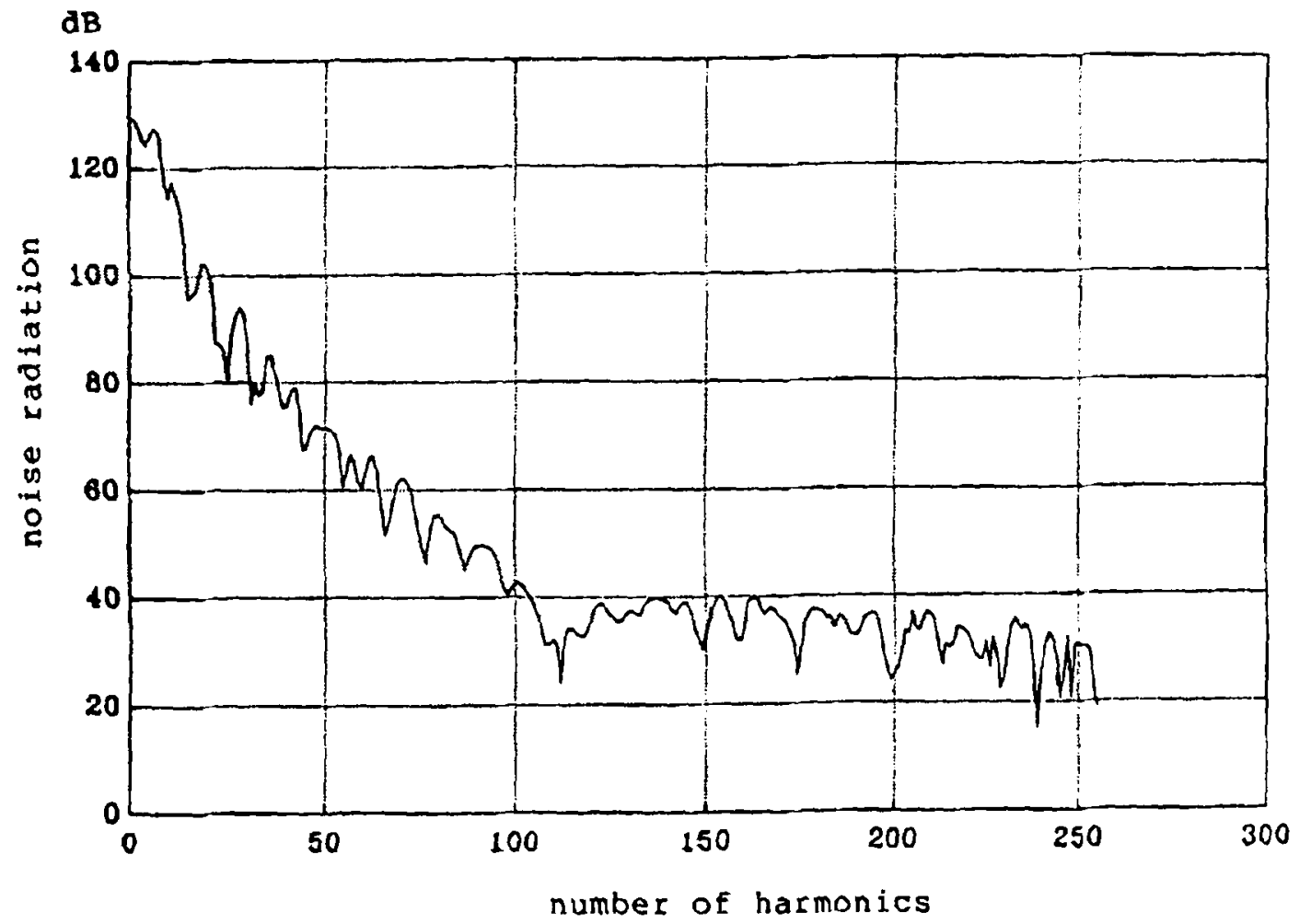

Figure 5. Noise radiated at $1 \mathrm{~m}$ distance from the radiation end, computed using the tail-pipe mass flux history obtained by the method of characteristics for an exhaust pipe of length $1 \mathrm{~m}$. 


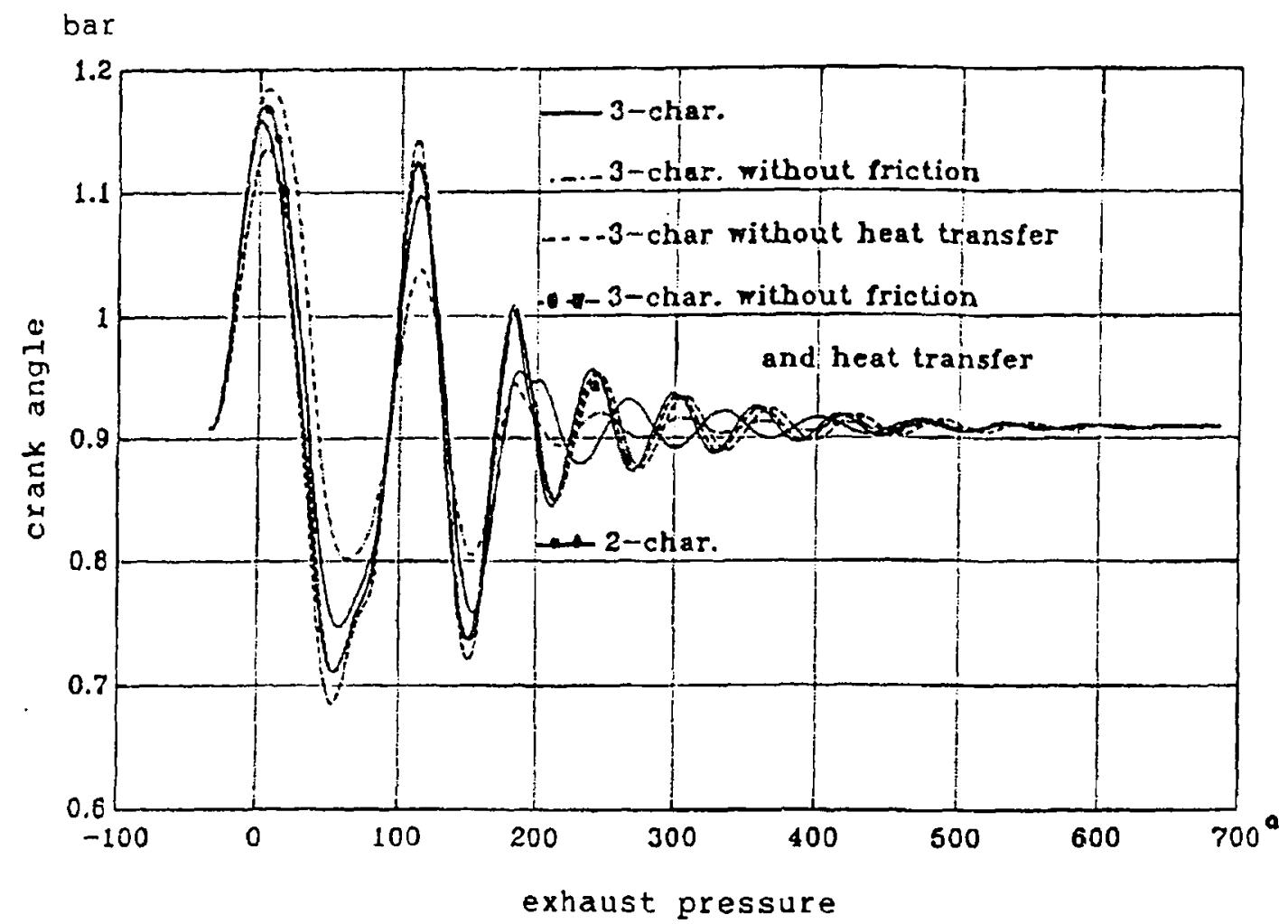

Figure 6. Effect of friction, heat transfer, and the two-characteristic method on the exhaust pressure-time history.

becomes more and more sensitive to the initial guess as the number of equations increase. This is in spite of the fact that the values corresponding to the previous instant are used as the initial guess for the present instant. This indicates that as the muffer complexity increases the incremental change per unit of incremental time also increases, thus rendering the initial guesses outside the domain of convergence. This too is quite expected.

Figures 2-5 show the exhaust pressure, the exhaust mass-flux history, the tail-pipe mass-flux history and the noise radiated at a distance of $1.0 \mathrm{~m}$, computed using the tail-pipe mass-flux history.

The simulated results for a simple pipe are compared for various cases in figure 6 . It is clear that though the effect of friction is quite low on the pressure-time history, the effect of heat transfer is substantial. The results of simulation using the twocharacteristic approximation (i.e. assuming an isentropic case) are quite close to the results obtained by neglecting friction and heat transfer. This is not obvious as one would expect entropy fluctuations at the cavity-pipe junction to have a sizable effect on the thermodynamic variables.

\section{Experimental corroboration}

In this section the model discussed in Gupta \& Munjal (1993) is corroborated with the experimental results. Similar experiments have been performed in the past for corroboration and are well documented (see, for example, Benson 1982). The main objective of the experimental investigation was to measure pressure in the exhaust 


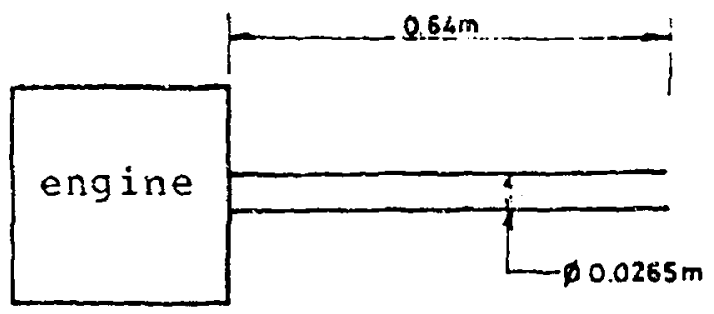

(a)

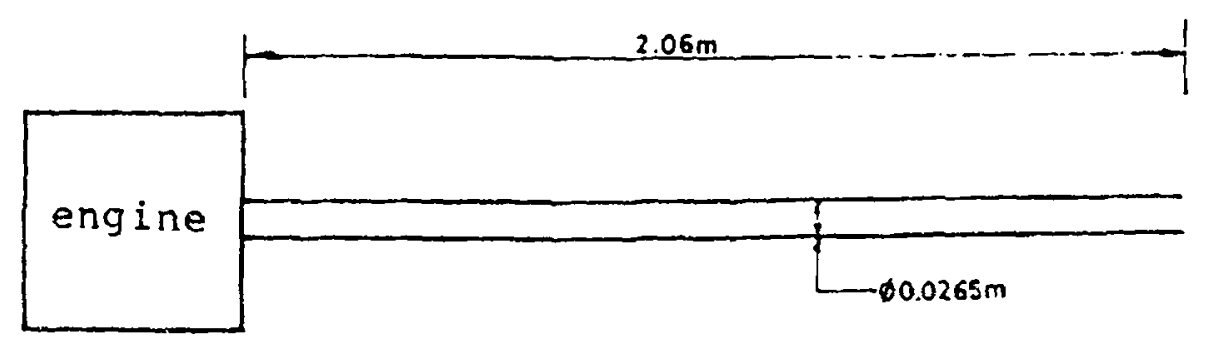

(b)

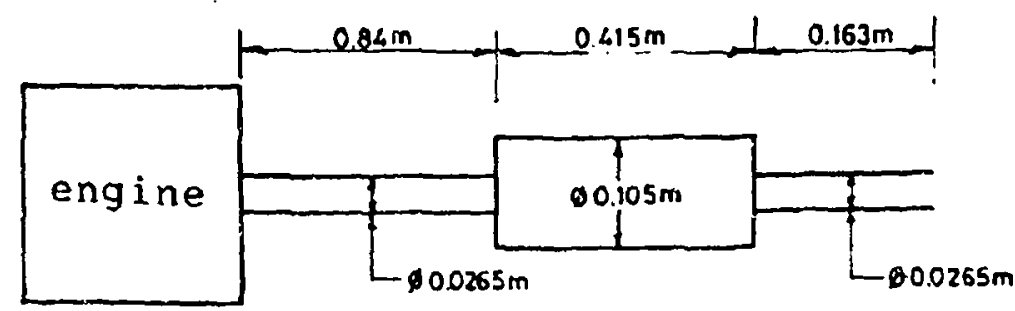

(c)

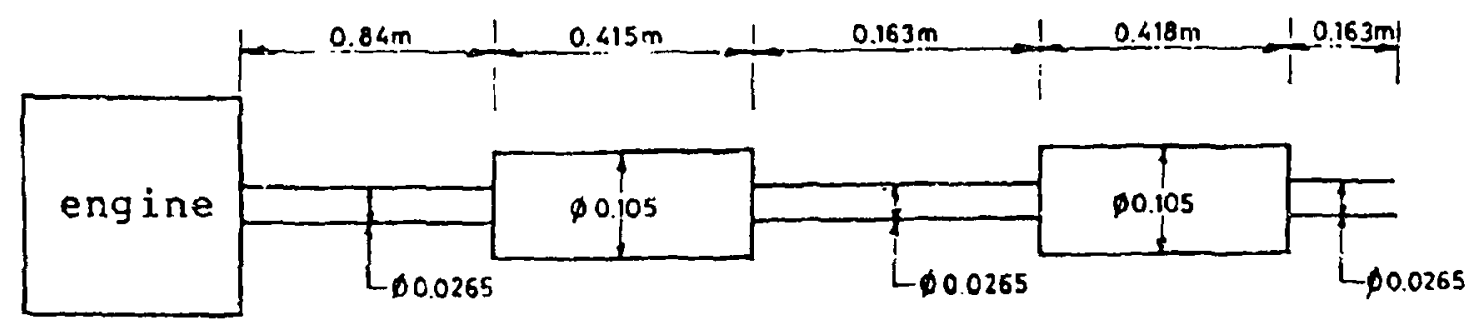

(d)

Figure 7. The muffler configurations. (a) Short pipe; (b) long pipe; (c) single chamber; (d) two chambers.

pipe. A few auxiliary measurements were made to get some data needed for the computational model, viz. the blow-down pressure, the blow-down temperature etc.

The experiments were conducted on a single-cylinder, four-stroke, naturallyaspirating diesel engine. Four different configurations of mufflers, namely, a short pipe, a long pipe, a single expansion chamber and two expansion chambers were used. These configurations are depicted in figure 7. Details of the engine are given in appendix $\mathbf{A}$.

The experimental investigation can be divided into two aspects. One involving the kinematic and geometric measurements on the engine and the other consisting of dynamic measurements. 


\section{Dynamic measurements}

Figure 8 illustrates the experimental setup schematically. A small hole was drilled to mount the piezo-electric pickup to measure the cylinder pressure. The piezo-resistive pickup (for the exhaust pressure) was mounted $0.1 \mathrm{~m}$ from the cylinder block. However, considering the length of the curved passage after the valve (in figure 9), the point is at approximately $0.2 \mathrm{~m}$ from the cavity-pipe junction. The signals picked up by the transducers were fed to a dual-channel signal analyser and were synchronized with the extra spike of the crank angle rotation.

The engine was run once in the motoring mode and then crank-angle and pressure transducers were synchronized for the top dead centre (TDC) to coincide with the pressure peak. Then, knowing the exhaust port opening time, the blow-down pressure was measured from the cylinder pressure vs crank angle diagram, obtained under
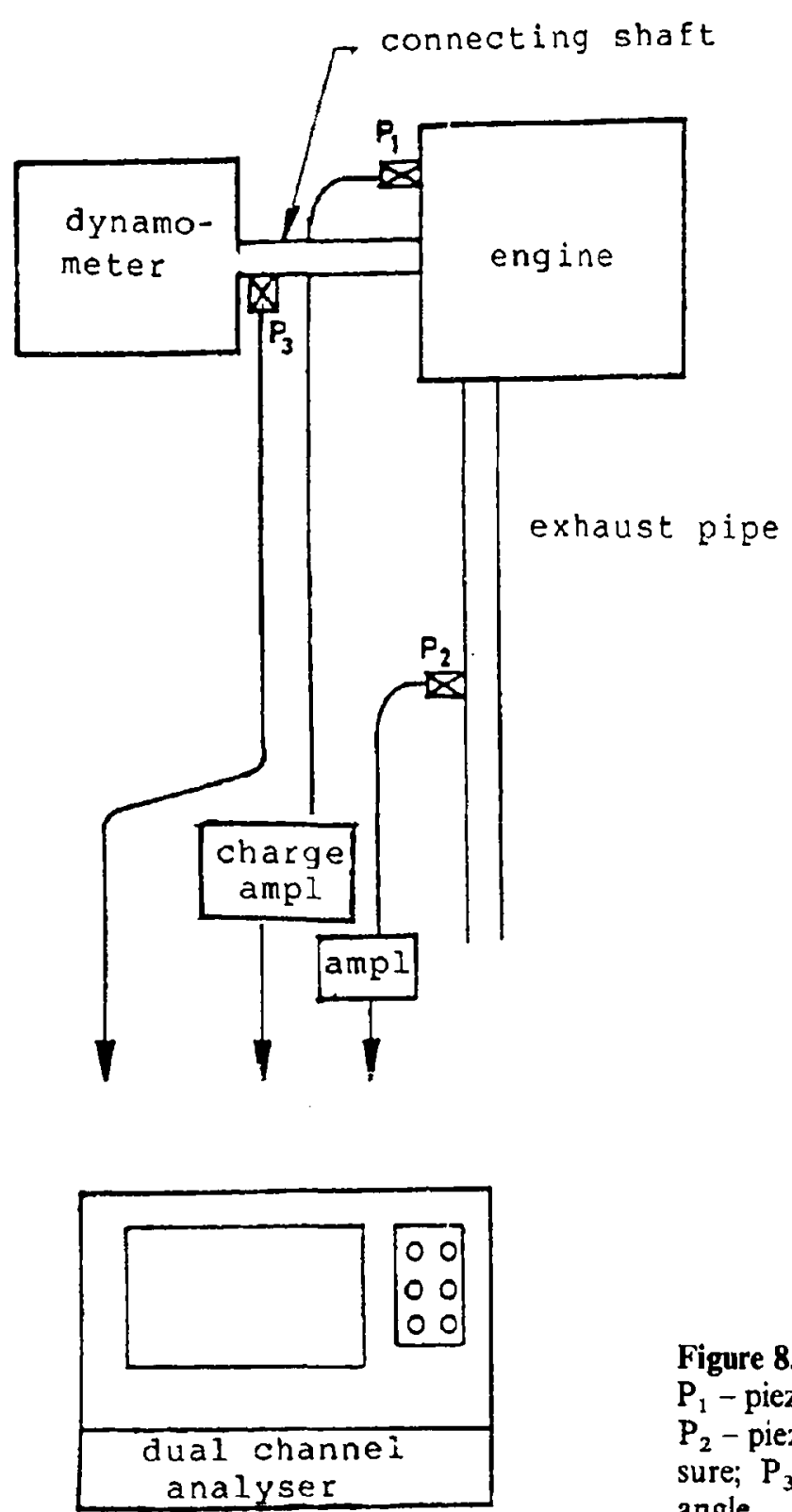

Figure 8. Schematic of the experimental setup: $\mathrm{P}_{1}$ - piezo-electric pick-up for cylinder pressure; $\mathrm{P}_{2}$ - piezo-resistive pick-up for exhaust pressure; $\mathrm{P}_{3}$ - electromagnetic pick-up for crank angle. 


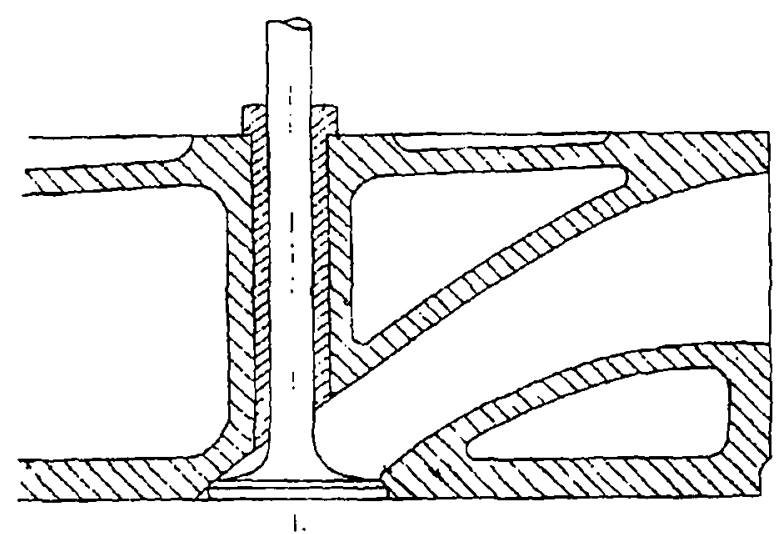

Figure 9. Schematic of an exhaust valve/port.

the firing mode. However, it was observed that the blow-down pressure in all the four configurations is more or less the same within experimental error. Hence, for the computer predictions, the same value (i.e., $0.3436 \mathrm{MPa}$ ) has been used for all configurations.

The exhaust pressure was recorded in synchronization with the crank-angle indicator.

The muffler wall temperature and the exhaust gas temperature at the tail pipe end were measured using a mercury thermometer. In accordance with expectations, the muffler wall temperatures came out to be quite the same at all locations with very minor variations.

Various geometric details of the mufflers used in the respective configurations are as shown in figure 7.

Temperatures vary rapidly in IC engines. These are obviously difficult to measure. The thermal inertia of the transducer is normally large. Also, in typical diesel engines, carbon deposition will significantly alter the heat transfer characteristics of the transducer itself. Extremely specialised and sophisticated instrumentation may also fall short of adequacy in such conditions. Fortunately, however, the blow-down temperature in a typical compression-ignition engine is known to be well behaved (Khovakh et al 1971). Also, it was observed that the computational model is not so sensitive to variations in the blow-down temperature. Kathuriya (1977) obtained blow-down temperature following a technique given by Khovakh et al (1971) and claimed it to be a good enough approximation. Nevertheless, such a calculation inherently involves a choice of some other parameters; to name a few, the polytropicexponent, the amount of exhaust gases trapped in the cylinder etc. Making a judicious choice of parameters is as difficult as the choice of blow-down temperature itself. Therefore, the blow-down temperature was assumed directly to be about $1300 \mathrm{~K}$, which is midway between the limits of 1200 and $1400 \mathrm{~K}$ indicated by Khovakh et al (1971) for diesel engines operating at the rated conditions.

\section{Comparisons and discussion}

Values of the blow-down pressure (0.346 MPa) and temperature $(1300 \mathrm{~K})$, valve area vs crank angle function ((3) and (1)), muffler dimensions and engine geometry (appendix A) were used as input to the computation scheme described in $\S 7$ of the accompanying paper (Gupta \& Munjal 1993). The program then was run to predict the pressure at 
bar

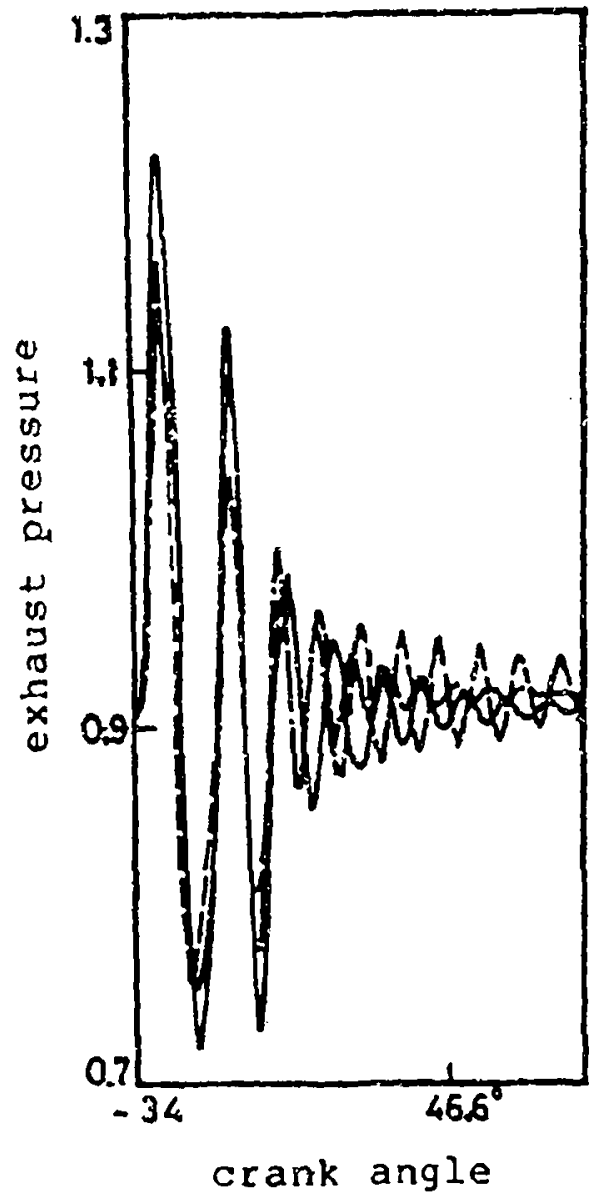

Figure 10. Comparison of exhaust pressure obtained by experiment and that predicted using the method of characteristics for the configuration of figure $7 \mathrm{a}$ [from computation (-), experiment $(-\rightarrow)$ and computation neglecting friction and heat transfer $(--)]$.

the exhaust pressure pick-up point (at $0.2 \mathrm{~m}$ from the cavity-pipe junction). The steady-state cycle results are used for comparison with the measured values.

Comparison of results from numerical prediction and experiments are presented in figures 10-13. Figures 10 and 11 present the comparison for the configurations shown in figures $7 \mathrm{a}$, and $7 \mathrm{~b}$, where the exhaust system consists of just an exhaust pipe. The effect of additional lengths corresponding to the end-correction, associated with the tail-pipe in the frequency-domain analysis, is not substantial, but the extra length due to the passage in the exhaust port makes some difference. As can be expected, this length is to be added to the length of the exhaust pipe external to the engine. Also, the distance of the pressure pickup gets modified accordingly. It is evident from figure 10 that the computed values get damped much faster than the experimentally observed values. Initially this was thought to be the effect of possible large heat transfer in the simulation, however, as is evident in the same figure, even in the absence of friction and heat transfer the damping is quite rapid. The results of the two-characteristics (isentropic approximation) solution were also found to be equally satisfactory. This confirms the conclusions of Jones et at (1986) where it has been claimed that on many occasions it is not necessary to use a fully nonlinear method for the required simulation. At the same time, it is also quite clear that further improvements in the corroboration can be obtained through fine tuning of the program parameters. Any better quantitative correspondence will possibly not involve any major qualitative or conceptual change. It has been shown that these changes anyway have little impact on the source characteristics evaluation (Gupta \& Munjal 1992). 

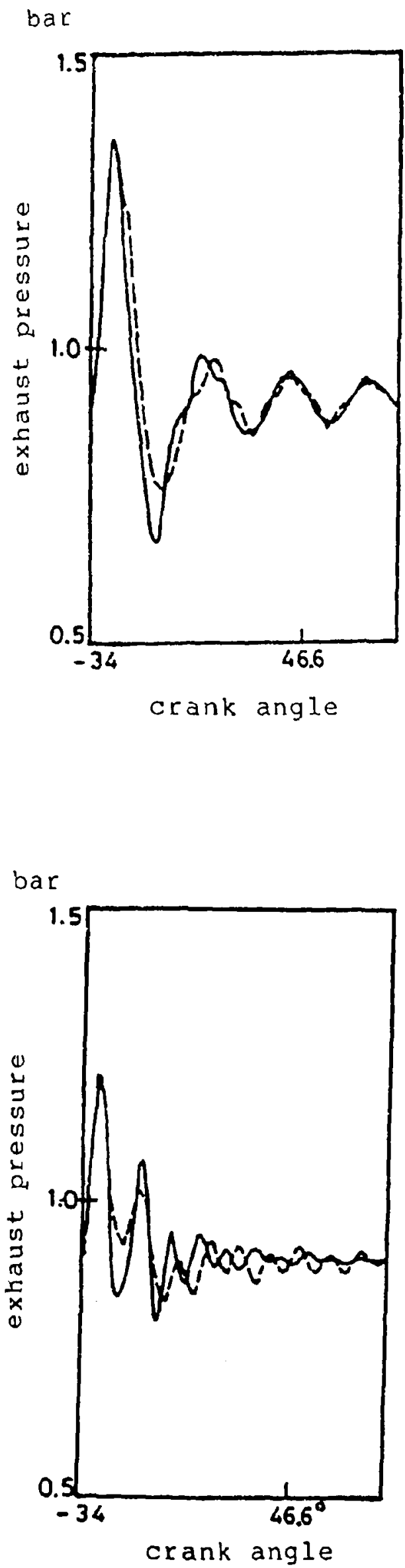

Figure 11. Comparison of exhaust pressure obtained by experiment and that predicted using the method of characteristics for the configuration of figure $7 \mathrm{~b}$ [from computation (-) and experiment (---)].
Figure 12. Comparison of exhaust pressure obtained by experiment and that predicted using the method of characteristics for the configuration of figure $7 \mathrm{c}$ [from computation (-) and experiment (--) ] 
bar

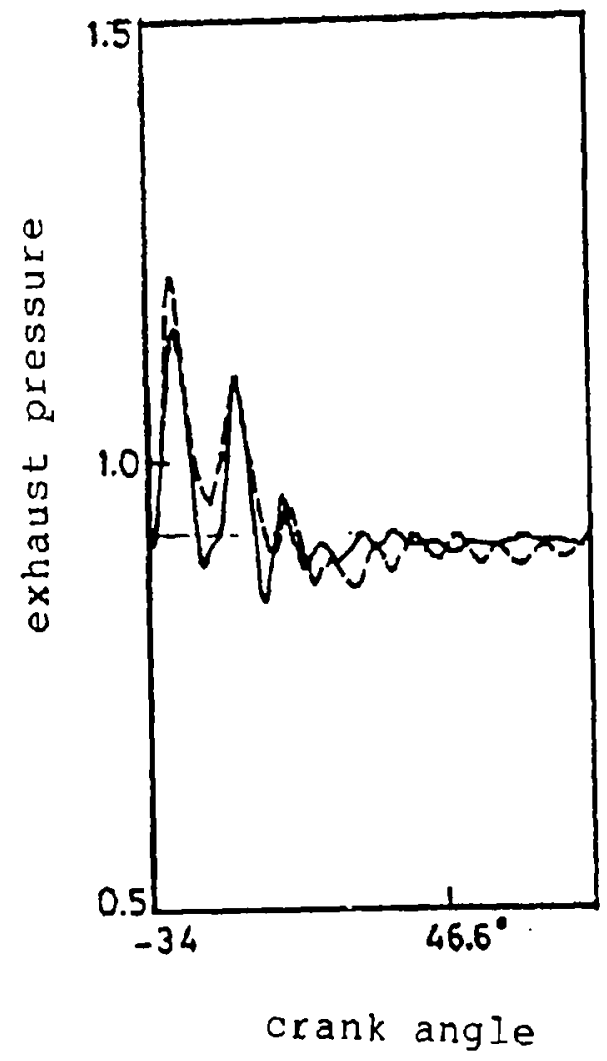

Figure 13. Comparison of exhaust pressure obtained by experiment and that predicted using the method of characteristics for the configuration of figure $7 \mathrm{~d}$ [from computation (-) and experiment (--) ].

This shows that even for the prediction of noise radiation any of the methods will yield a good enough result in the sense that it will at worst be only as bad as by any other technique. This is in conflict with the claim in Munjal \& Jayakumari (1983) that the acoustic performance of an engine is quite sensitive to the effect of friction and heat transfer.

The comparisons for the configurations shown in figures $7 \mathrm{c} \& \mathrm{~d}$, are presented in figures 12 \& 13 respectively. The comparisons show that the computed results are generally in decent agreement with the experimental ones. Besides, in the light of the fact stated in the previous paragraph about the marginal sensitivity of the desired acoustical performance parameters to the simulation parameters, the apparent discrepancies also lose significance.

It should be noted, however, that certain other parameters like the mean tail-pipe temperature, the mean tail-pipe Mach number etc. are affected significantly by these differences in the simulation parameters. Therefore, any decision involving the evaluation of parameters has to be made after judicious deliberation. The thumb rule can be that any parameter involving temperature will certainly be affected by variations in the simulation parameters. Moreover, since in general all the variables are thermodynamically or gas-dynamically interrelated, their detailed history will usually differ in such cases. However, the average performance parameters are not substantially affected by these variations in the detailed history, probably because of the fact that both the forward wave and the rearward wave are affected similarly by the changes. This affects both the peaks as well as the troughs in the history in a qualitatively similar fashion. Therefore, in the evaluation of average parameters, these effects get cancelled. But this argument holds no ground for the acoustical performance 
parameters because an enlargement or a contraction, though equally of peaks and troughs, should in principle cause large changes in the acoustical parameters, for the simple reason that basically acoustic parameters are about these peaks and troughs. However, what actually happens is that this visual or apparent change in the peaks and troughs causes significant change only in the first two or three harmonics in the Fourier transform. Besides, at these frequencies the noise radiated is anyway very high. Yet the finer details of the acoustical parameters do get changed by these variations (Gupta \& Munjal 1992).

Another feature that can be observed from figures 10 and 11 is that the simulation results compare with the experimental results much better for a longer pipe than for a shorter pipe. In case of the shorter pipe the computational results damp out much more rapidly whereas this effect is not as pronounced in the case cf a longer pipe. This is most probably due to the fact that the radiation end condition applied in time-domain analysis, that of the pressure being same as that in the atmosphere, is not correct. In reality, the waves encounter a radiation impedance which is difficult to model in time-domain analysis. It may be suggested that the radiation reactance can be incorporated by taking an additional length. However, as pointed out earlier, the effect of such an additional length was observed to be quite negligible. On the contrary, the effect of radiation resistance which dissipates some amount of energy into the atmosphere appears to be more significant than the effect of the additional length. This, in turn, indicates that the radiation end condition in the time-domain analysis requires further investigation. Also, the acuteness of the discrepancy in the shorter pipe may be explained by the fact that for a-shorter pipe the number of times the waves travel across the whole length and encounter the open end are more than in the longer pipe. This in turn confirms the hypothesis that the discrepancy is due to the improper radiation-end conditions.

\section{Concluding remarks}

- As indicated in $\S 3$ (part $I$ ), the implementation of the stationary-frame method in Munjal (1987) is in violation with the basic governing equations owing to an inexact combination of the schemes developed and implemented by Benson (1982), and Jones \& Brown (1982). Also, for the cavity-pipe junction the set of equations described in Munjal (1987) are incomplete and incompatible as described in $\$ 4.1$ of Gupta \& Munjal (1993) (part I). These discrepancies were corrected by adoption of a correct approach for the interpolation of the entropy variable as is described in $\$ \S 3$ and 4.1 of part $I$.

- In the model for a cavity-pipe junction, pressure recovery has been neglected. However, in the actual situation, owing to the fact that the ports are designed with smooth area profiles, pressure recovery cannot be ruled out. An investigation into the details of the effect of pressure recovery on the prediction performance of the model needs to be undertaken.

- Simple area discontinuities can be modelled using either the stagnation pressure loss model of Munjal (1987), or the momentum equation model of Benson (1982). As shown in $\S 4.3$ (part I), the pressure loss model appears to be superior to the other inasmuch as it is derived using experimentally obtained loss factors as against the other which violates the experimental observations for sudden contraction where the pressure on the annular end plate is assumed to be equal to the upstream stagnation pressure. 
- The effect of wall-friction and heat transfer in the exhaust gas flow on the thermodynamic performance of the engine has been reported in the literature to be negligible. Also, it has been claimed in Munjal \& Jayakumari (1983) that the acoustic performance is substantially altered by the presence of friction and heat transfer. However, as shown in $\$ 5$ this claim is not very well founded and should not be taken at face value.

- The formulae for friction and heat transfer suffer from an inherent weakness inasmuch as they are valid oniy for steady flow processes, and, therefore, their application to pulsating flow is questionable. However, as pointed out in $\S 6$ (part I) any suitable correlation can be used because different correlations do not yield substantially different results.

- From the results presented in $\S 5$ it is suggested that time-domain analysis falls short of properly incorporating the radiation end conditions. This calls for further investigation in the relationship between the frequency-domain radiation-end conditions and the time-domain radiation-end conditions. Such effects were observed to be more pronounced for shorter pipes than for longer ones.

The experimental part of the investigation was carried out using instruments presented by Stiftung Volkswagenwerk, Hannover, Germany under their joint project with one of the authors (MLM) and with Prof M Heckl of Technische Universitat, Berlin (Germany) as the collaborating scientists.

\section{Appendix A. Engine specifications}

The details of the engine used for the model are given below:

Kirloskar type AV1, single cylinder, water-cooled, vertical, four-stroke, open combustion chamber, naturally aspirating diesel engine.

$\begin{array}{ll}\text { Ratel brake power } & 5 \text { h.p. } \\ \text { Rated speed } & 1500 \mathrm{rpm} \\ \text { Nominal compression ratio } & 16: 1 \\ \text { Bore } & 0.08 \mathrm{~m} \\ \text { Stroke } & 0.11 \mathrm{~m} \\ \text { Connecting rod length } & 0.23 \mathrm{~m}\end{array}$

Valve timings (cold setting)

Exhaust valve opening (EVO) : $34^{\circ}$ before BDC

Inlet valve opening (IVO) : $175^{\circ}$ after BDC

Exhaust valve closing (EVC) : $195^{\circ}$ after BDC

Here, BDC connotes bottom dead centre.

A schematic of the exhaust port is shown in figure 9. The inlet port is similar to it. The valve area as a function of the crank angle was also computed and the relations are given by

$$
\text { exhaust area }=\sum_{i=1}^{i=7} E_{i} \Delta \theta^{i-1},
$$


where $\Delta \theta$ in $A 1$ is given by

$$
\Delta \theta=\theta-\theta_{\mathrm{EVO}} \text {, or by } \Delta \theta=\theta_{\mathrm{EVO}}-\theta
$$

whichever is less, and that for the inlet port is given by

$$
\text { inlet area }=\sum_{i=1}^{i=8} I_{i} \Delta \theta^{i-1}
$$

where $\Delta \theta$ in $(A 3)$ is given by

$$
\Delta \theta=\theta-\theta_{1 \text { พ० }} \text {. }
$$

In both the expressions, $\theta$ is the crank angle in degrees measured from the bottom dead centre of the engine:

The values of the polynomial coefficients are

and

$$
\begin{array}{ll}
E_{1}=0.5368 \times 10^{-6} ; & E_{2}=2.1691 \times 10^{-6} ; \\
E_{3}=0.01506 \times 10^{-6} ; & E_{4}=0.00594 \times 10^{-6} ; \\
E_{5}=-0.1075 \times 10^{-9} ; & E_{6}=0.6195 \times 10^{-12} ; \\
E_{7}=-0.1065 \times 10^{-14} ; &
\end{array}
$$

$$
\begin{array}{ll}
I_{1}=-0.5165 \times 10^{-6} ; & I_{2}=0.9667 \times 10^{-6} \\
I_{3}=0.03676 \times 10^{-6} ; & I_{4}=0.004035 \times 10^{-6} \\
I_{5}=-0.2391 \times 10^{-10} ; & I_{6}=-0.7906 \times 10^{-12} \\
I_{7}=0.9281 \times 10^{-14} ; & I_{8}=-0.2796 \times 10^{-16}
\end{array}
$$

\section{References}

Benson R S 1982 The thermodynamics and gas dynamics of internal combustion engines (Oxford: Clarendon Press)

Gupta V H 1991 On the flow-acoustic modelling of the exhaust system of a reciprocating internal combustion engine. Ph D thesis, Indian Institute of Science, Bangalore

Gupta V H, Munjal M L 1992 On numerical prediction of the acoustic source characteristics of an engine exhaust system. J. Acoust. Soc. Am. 92: 2716-2725

Gupta V H, Munjal M L 1993 Time-domain-finite-wave analysis of the engine exhaust system by means of the stationary-frame method of characteristics. Part I. Theory. Sädhanä 18: 911-925

Jones A D, Brown G L 1982 Determination of two-stroke engine exhaust noise by the method of characteristics. J. Sound Vibration 82: 305-327

Jones A D, Van Moorhem, Voland R T 1986 Is a full nonlinear method necessary for the prediction of radiated engine exhaust noise? Noise Control Eng. J. 26: 74-80

Kathuriya M L 1977 Experimental evaluation of the acoustic impedance of a termination in stationary or moving medium with particular application to the exhaust system of an IC engine. $\mathrm{Ph} \mathrm{D}$ thesis, Indian Institute of Science, Bangalore

Khovakh M, Arkhangelsky V, Stepanov Y, Trusov V, Vikhert M, Voinov A 1971 Motor vehicle engines (ed.) M Khovakh (Moscow: Mir Publishers)

Munjal M L 1987 Acoustics of ducts and muffers (New York: John Wiley and Sons)

Munjal M L, Jayakumari H B 1983 Numerical evaluation of aeroacoustic characteristics of an interral combustion engine by means of finite wave analysis. Report DST:ME:MLM:59/R-1, Indian Institute of Science, Bangalore 